\title{
INFLUENCE OF ROTATIONAL STIFFNESS OF SUPPORT OF A PARTIALLY TENSIONED COLUMN ON ITS FREE VIBRATIONS
}

\author{
S. Uzny*, M. Osadnik ${ }^{* *}$
}

\begin{abstract}
In this paper the theoretical and numerical studies on transversal vibrations of partially tensioned column are presented. The discussed structure corresponds to the screw drive system which is used in cranes. The formulated boundary problem allows one to calculate the vibration frequency. In this manuscript only an influence of the rotational stiffness of the support on linear component of vibration frequency is discussed. Moreover the differential equation and boundary condition are given to present the behavior of the structure at linear vibrations. The results of numerical simulations are concern on linear component of vibrations in relation to the location of external load application and different rotational stiffness of the support.
\end{abstract}

Keywords: slender systems, stability, spring elements, Euler's load

\section{Introduction}

In the design process of slender systems (columns (Kounadis 1981, 1983, Ryu et al., 2000, Sundararajan, 1976)) which are subjected to the axial loads it is important to verify the dynamical properties such as vibration frequency which highly depends on many parameters of the structure. In many cases such systems are exposed to excitations causing an increase in amplitude of vibration above the safe level. Amplitude of transversal vibrations contributes directly to the destruction of the system due to material fatigue. During such vibrations the temporary exceeding of stress above the limit of fatigue takes place but in long term exploitation it can have very serious consequences. The destruction of the slender system may contribute to economic losses as well as to the loss of health and even lives of people directly related to this type of structures. The mentioned hazards are present because slender systems are components of support structures (columns (Tomski, 1985, Tomski and Uzny, 2008, Uzny, 2011, Uzny and Sokól, 2015, Sokół, 2014, Sokół and Uzny, 2016)) and cranes (actuators (Uzny et al., 2017, Sochacki and Tomski, 1999)). For this reason, structures are examined in terms of the shape of characteristic curves, i.e. curves determining the relationship between the magnitude of the load and the natural vibration frequency (comp. Tomski and Uzny, 2008). In the literature one can find characteristic curves, which correspond to various cases of conservative load - considered in this work. The most classic shape has a divergence curve, which is associated with the Euler load (during the deflection of the system the line of action of the force does not change). In this case, the natural frequency decreases with increasing load (comp. Uzny, 2011). Another type of characteristic curve is a divergence - pseudoflatter one (associated with Tomski's load - comp. Tomski and Uzny, 2008). In this case, the natural frequency can both increase as well as decrease with the load (the relation depends on the load parameters). By means of Tomski's load it is possible to control the dynamic properties of slender systems without changing the main elements of the structure. Systems in which vibrations can be generated by the system itself (self-excited vibrations) are the drive systems such as screw-nut drive ones. Screw mechanisms are used in elevator systems (personal

\footnotetext{
Sebastian Uzny, Prof.: Institute of Mechanics and Machine Design Foundation, Częstochowa University of Technology Dąbrowskiego 73, 42-200 Częstochowa, Poland, uzny@imipkm.pcz.pl

** Michał Osadnik, MSc.: Institute of Mechanics and Machine Design Foundation, Częstochowa University of Technology Dąbrowskiego 73, 42-200 Częstochowa, Poland, m.osadnik@imipkm.pcz.pl
} 
or cargo lifts). In this type of construction, screws are subjected to an axial load affecting the frequency of natural vibrations. On the natural vibration frequency affects not only the load value but also the place of its application. In papers Uzny et al. (2016a, 206b), Uzny and Osadnik (2017b) an investigations in natural frequency magnitude in relation to the load magnitude (compression of one part and tension of the other) and location were done. An important element of the research was to determine the stability of the screw as a slender system (see Uzny and Osadnik, 2017a). In publications Uzny et al. (2016b) and Uzny and Osadnik (2017b) an influence of the vibration amplitude on vibration frequency has been calculated. The partially tensioned systems were considered as fixed on both ends columns (Uzny et al., 2016b) and as longitudinal elastic supports columns (Uzny and Osadnik, 2017b) (an influence of translational longitudinal stiffness placed on one end on natural linear and nonlinear vibrations). On the basis of the performed studies it has been stated that the vibration frequency is related to the location of external load as well as to the stiffness of the used elastic elements in the supports.

The main scope of this study is to investigate an influence of the rotational stiffness of the support on basic vibration frequency which does not depend on amplitude.

\section{Boundary problem}

The discussed boundary problem is given in figure 1 . The partially tensioned column models the structure composed of screw and nut which is loaded with external force $P$. The mathematical model consists of two rods (marked with indexes 1 and 2) of length $l_{1}$ and $l_{2}$ with equal stiffness. In the point of connection of rods the nut is paced (point $O$ ) which is loaded with the force $P$ (constant line of action). Additionally the translational springs are introduced (stiffness $k_{0}$ and $k_{1}$ ) located along the axis of the column and rotational springs (stiffness $C_{0}$ and $C_{1}$ ). Springs are marked as 0 and 1 , where 0 stand for $x_{1}=0$ while 1 refers to $x_{2}=l_{2}$. Springs are used to limit the longitudinal displacements as well as rotations on both ends.

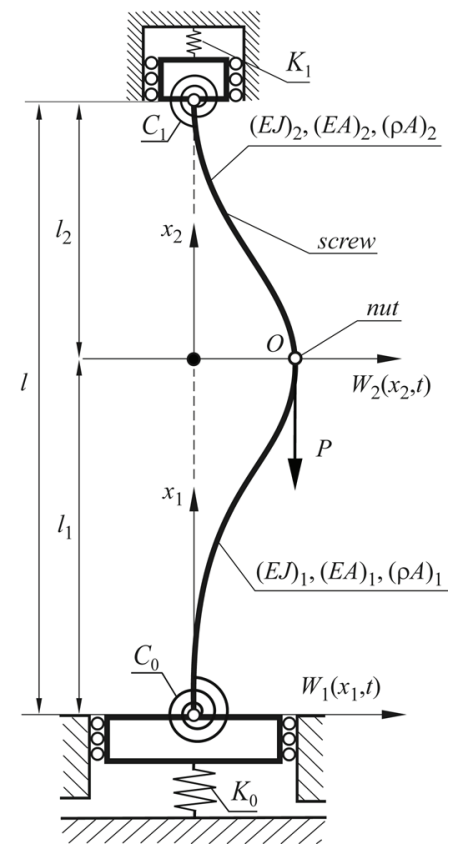

Fig. 1: Physical model of investigated system.

In this paper only the differential equations and corresponding boundary conditions on the basis of which the linear component of vibration frequency can be calculated are presented. The discussion is limited to the first vibration frequency, which has great importance at resonance. The further vibration frequencies have great magnitudes. That is why they are omitted in this paper.

The differential equations of motion in transversal direction and equations of longitudinal ones are as follows (using the method of separation of variables and Bernoulli-Euler beam theory):

$$
W_{i 1}^{I V}\left(x_{i}\right)+\frac{S_{i 0}}{(E J)_{i}} W_{i 1}^{I I}\left(x_{i}\right)-\frac{(\rho A)_{i} \omega_{0}^{2}}{(E J)_{i}} W_{i 1}\left(x_{i}\right)=0 ; U_{i 0}\left(x_{i}\right)-U_{i 0}(0)=-\frac{S_{i 0}}{(E A)_{i}} x_{i}
$$


where: $U_{i 1}\left(x_{i}\right), W_{i 1}\left(x_{i}\right)$ - longitudinal displacement caused by external force and transversal displacements during vibrations, roman numerals stand for row of the derivative with respect to variable $x_{i} ; S_{i 0}$ is an internal force in $i$-th $\operatorname{rod} ;(\rho A)_{i},(E J)_{i},(E A)_{i}$ - mass per length unit, bending stiffness, compression stiffness respectively $\left((\rho A)_{1}=(\rho A)_{2} ;(E J)_{1}=(E J)_{2} ;(E A)_{1}=(E A)_{2}\right) ; \omega_{0}$ - basic component of natural frequency of transversal vibration.

The boundary conditions are given in the form:

$$
\begin{aligned}
W_{10}(0)= & W_{20}\left(l_{2}\right)=0 ; U_{10}\left(l_{1}\right)=U_{20}(0) ; W_{10}\left(l_{1}\right)=W_{20}(0) ; W_{10}^{I}\left(l_{1}\right)=W_{20}^{I}(0) ;(E J)_{1} W_{10}^{I I}(0)-C_{0} W_{10}^{I}(0)=0 \\
& -(E J)_{1} W_{10}^{I I}\left(l_{1}\right)+(E J)_{2} W_{20}^{I I}(0)=0 ; \quad(E J)_{1} W_{10}^{I I I}\left(l_{1}\right)-(E J)_{2} W_{20}^{I I I}(0)+S_{10} W_{10}^{I}\left(l_{1}\right)-S_{20} W_{20}^{I}(0)=0 \\
- & (E J)_{2} W_{20}^{I I}\left(l_{2}\right)-C_{1} W_{20}^{I}\left(l_{2}\right)=0 ; S_{10}-S_{20}-P=0 ; S_{20}-k_{1} U_{20}\left(l_{2}\right)=0 ; S_{10}-k_{0} U_{10}(0)=0
\end{aligned}
$$

The solution of the differential equations (1a) supplemented with boundary conditions leads to estimation of basic component of natural frequency in case of transversal vibration.

\section{Results of numerical simulations}

The results of numerical calculations are presented in the non-dimensional form by means of the following parameters:

$$
\lambda=\frac{P l^{2}}{(E J)_{1}} ; c_{j}=\frac{C_{j} l}{(E J)_{1}} ; k_{j}=\frac{K_{j} l^{3}}{(E J)_{1}} ; \zeta=\frac{l_{1}}{l} ; \Omega_{0}=\frac{\omega_{0}^{2}(\rho A)_{1} l^{4}}{(E J)_{1}}
$$
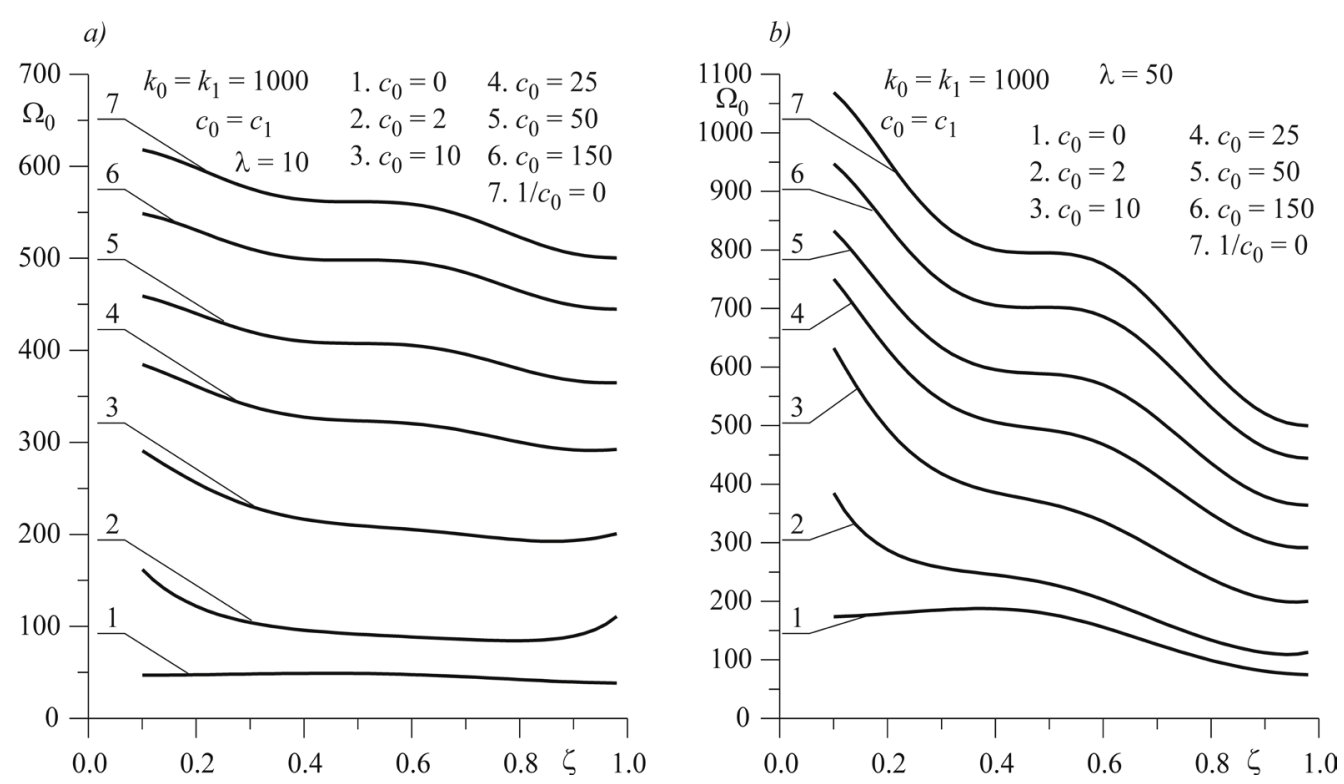

Fig. 2: The relationship between linear component of the free vibration frequency $\Omega_{0}$ and external load application point

In the figure 2 the change in linear component of vibration frequency in relation to the $\zeta$ parameter which shows the location of the point of application of external load (location of the nut) is plotted. Calculations were performed at the same support conditions $x_{1}=0$ and $x_{2}=l_{2}\left(k_{0}=k_{1} ; c_{0}=c_{1}\right)$. In simulations it has been assumed that translational stiffness is $k_{0}=k_{1}=1000$, external load magnitude $\lambda=10$ (figure 2a) and $\lambda=50$ (figure 2b) and rotational stiffness $c_{0}=c_{1}=0 ; 2 ; 10 ; 25 ; 50 ; 150 ; 1 / \mathrm{c}_{1}=0$. On the basis of the performed simulations it has been shown that the rotational stiffness has great influence on the magnitude of vibration frequency. At given rotational stiffness the vibration frequency changes in relation to the location of the external force application point. The greater the rotational stiffness the greater difference in vibration magnitude at different locations of the nut can be observed. Similar effect has the magnitude of the external load - the greater the load the greater difference in vibration frequency. 


\section{Conclusions}

In this study an influence of the rotational stiffness of the support of both ends on vibrations of screw drive system are presented. Only the linear component of vibrations is discussed which is independent from amplitude of vibrations. The great influence of rotational stiffness on linear component of vibrations at different locations of external load application and magnitude has been found. An increase in external load magnitude results in more dynamic response of the investigated parameter. The results of this study can be applied during the design of the drive units of cranes. The studies can be continued when additional parameters which have an influence on the stability of the structure will be introduced into the mathematical model. In the future research an influence of amplitude on vibration frequency at different rotational stiffness of the support will be discussed.

\section{Acknowledgement}

The study has been carried out within the statutory funds of the Czestochowa University of Technology BS/PB 1-101/3020/17/P and BS/MN 1-101-306/17/P.

\section{References}

Kounadis, A.N. (1981) Divergence and flutter instability of elastically restrained structures under follower forces, Int. J. Engng. Sci. 19(4), 1981, 553-562.

Kounadis, A.N. (1983) The existence of regions of divergence instability for nonconservative systems under follower forces, Int. Journal Solids Structures, 19(8), 1983, 725-733.

Ryu, J.B., Sugiyama, Y., Yim, K.B. and Lee, G.S. (2000) Dynamic stability of an elastically restrained column subjected to triangulary distributed subtangential forces, Computers \& Structures, 76, 2000, 611-619.

Sochacki, W. and Tomski, L. (1999) Free Vibration and Dynamic Stability of a Hydraulic Cylinder Set. Machine Dynamics Problems, 23(4), 91-104.

Sokół, K. (2014) Linear and Nonlinear Vibrations of a Column with an Internal Crack, Journal of Engineering Mechanics, 140(5), http://dx.doi.org/10.1061/(ASCE)EM.1943-7889.

Sokół, K. and Uzny, S. (2016) Instability and vibration of multi-member columns subjected to Euler's load, Archive of Applied Mechanics, 86 (5),883-905, DOI: 10.1007/s00419-015-1068-6

Sundararajan, C. (1976) Influence of an elastic end support on the vibration and stability of Beck's column, Int. J. Mech. Sci. 18, 1976, 239-241.

Tomski, L. and Uzny, S. (2008) Free vibration and the stability of a geometrically non-linear column loaded by a follower force directed towards the positive pole, International Journal of Solids and Structures, 45, 87-112

Tomski, L. (1985) Prebuckling Behaviour of Compound Column - Direct Nonlinear Analysis, Z. Angew. Math. U. Mech., 65(1), 59-61.

Uzny, S., Sokół, K. and Osadnik, M. (2016a) Free vibrations of the partially tensioned geometrically non-linear system subjected to Euler's load, Vibrations in Physical Systems, 27, 399-406.

Uzny, S. (2011) Local and global instability and vibrations of a slender system consisting of two coaxial elements, Thin-Walled Structures, 49, 618-626.

Uzny, S. and Osadnik, M. (2017a) Influence of longitudinal elastic support on stability of a partially tensioned column, In: Engineering Mechanics 2017, Brno University of Technology, Brno, 1006- 1009.

Uzny, S. and Osadnik, M. (2017b) Influence of the longitudinal spring element on free vibrations of the partially tensioned column, Procedia Engineering, 17, 135-140

Uzny, S. and Sokół, K. (2015) The Bernoulli-Euler and Timoshenko Theories in the Context of Research on the Characteristic Curves of Column with Different Boundary Conditions, Proceedings of the International Conference of Numerical Analysis and Applied Mathematics 2014 (ICNAAM-2014) Book Series: AIP Conference Proceedings, Vol. 1648

Uzny, S., Sokół, K. and Kutrowski, Ł. (2017) Stubility of a hydraulic telescopic cylinder subjected to Euler's load, Proceedings of the 13th International Scientific Conference: Computer Aided Engineering book series: Lecture Notes in Mechanical Engineering, 581-588

Uzny, S., Sokół, K. and Osadnik, M. (2016b) Influence of amplitude on free vibration frequency of a partially tensioned column. In: Engineering Mechanics 2016, IT AS CR, Prague, 562-565. 